\title{
The Factor Specificity and the Exchange Rate Theory of Purchasing Power Parity: An Extension of the J ones-Purvis Model
}

\author{
Juan Antonio García-Cebro* \\ University of A Coruña
}

\begin{abstract}
The focus of this paper is on the structural aspects of exchange rate determi nation, generalizing the 1983 Jones-Purvis model. Specifically the Jones-Purvis model is extend to incorporate the concept of factor specificity. It is shown that deviations from purchasing power parity depend on, among other determi nants, factor specificity. Furthermore, it examines the factor specificity as a short-medium run determinant of the behavior of exchange rates, in a frame work where two countries are affected by a common external shock. (JEL clas sification: F 11, F 31)
\end{abstract}

\section{Introduction}

In the field of international economics there is a consensus among economists in that purchasing power parity theory does not adequately explain

\footnotetext{
* Correspondence Address: Facultade de Ciencias Económicas e Empresariais, Departamento da Analise Economica, Campus da Zapateira, A Coruña 15071, Spain, (Tel) 981-167050, (Fax) 981-167070, (E-mail) jagc@udc.es. This paper is taken from a chapter of my doctoral dissertation. I wish to thank to Zenón J. Ridruejo for his advise.
} 
the behavior of exchange rates in the short-run. ${ }^{1}$ Some of the factors for the deterioration in the explanatory power of PPP theory were due to structural change, expectations, changes in taste and in technology, and speculation. However, in recent years (over the past ten years), the debate about PPP, as a long-run relationship, has concentrated, partly due to innovations in econometrics and to the development of new data sets, on empirical issues rather than on the theory itself.

Froot and Rogoff [1995 p.1683], in an excellent survey, conclude that "there does seem to be long-run convergence to PPP," though further work on the issue of survivor-ship bias would be valuable". ${ }^{3}$

On the other hand is the literature that attempts to explain empirically deviations from PPP focusing on the structural or real aspects and the existence of non tradable commodities. ${ }^{4}$ In this context, the focus is on disturbances (productivity differentials, government spending and strategic pricing decisions by firms) which involve the possibility of relative price changes.

In this framework where changes in relative prices are significant determinants of real exchanges rates in the short-run and (perhaps) long-run, is developed the 1983 J ones-Purvis model. This model is a theoretical issue in which the permanent PPP violations in the long-run can be justified. The main feature of this approach is the segregation of local economic activity into two "tiers": 5 in the "input-tier," using capital and labor, middle products traded on world markets are produced. On the other hand is the "output:ier" where a middle product imported is combined with local labor to pro-

1. See, for example, Frenkel [1981], Adler and Lehman [1983], Aizenman [1984], Dornbusch [1985] and Daniel [1986] among others.

2. M ore recently, Frankel and Rose [1996], and Wei and Parseley [1995] find a half life for PPP deviations of roughly four years. Likewise, M acdonall [1996] and Snell [1996] seem to confirm the PPP hypothesis.

3. See, for example, M ark [1990], and Sharma and Obar [1995].

4. Froot and Rogoff [1995] review some of the key theoretical issues and their empirical evidences. They begin with Balassa [1964] and Samuelson [1964] and continue with the works of H sieh [1982], M arston [1987], Asea and M endoza [1994], and De Gregorio, Giovannini and Wolf [1994 a], among others. Furthermore, same other 
duce non-traded consumption goods. Assuming that there are two small ${ }^{6}$ countries both exporting a middle product $B$ and importing a middle product $A$, the J ones-Purvis model studies the effect of external common shock such as an increase in the world markets of the A price on the behavior of exchange rates. Furthermore, balanced trade is assumed. After this analysis, Jones and Purvis [ 1983 p. 54] concluded that "international differences in technology and structure cause international differences in responses of local factor rewards in response to common disturbances, creating international differences in movements in exchange rate-adjusted national price levels, reflected in what we have called the PPP discrepancy".

The purpose of this paper is to develop a more general approach in which the assumption of factor specificity is added in. By "specificity" we make reference to certain "characteristics" or "qualities" of production factors which obstruct their free mobility across industries of the economy. The property of "specificity" should not be conceived of as a wholly technological matter. Following B hagwati and Srinivasan [1983] two types of specificity are distinguishable: first, an aptitudinal specificity whereby a factor of production has a comparative aptitudinal advantage in producing one good rather than another. This type of specificity was reflected by Kierzkowski [ 1987 p. 5] as he pointed out: "A Ph. D in physics can easily transfer from employment in a personal computer company in the Silicon Valley, California to the Space Research Laboratory of Boeing in Seattle, Washington, but he cannot easily become a heart surgeon or even a hospital nurse". Second, a preferential specificity when a factor prefers being employed in one sector rather than another. Pitchfor [1967] already studied how differential changes in wages can arise with reference to the preferences of workers among occupations, and workers may be reluctant to shift among occupations. Hence, specificity in the former case is defined to be technology-based, whereas it is tastebased in the latter case. Although these two distinct approach might have different implications on certain analyses (for example, in the evaluation of trade policies), in this paper I will obviate the difference between the two alternative conceptions of specificity. 
The assumption of factor specificity was introduced in the international trade theory by means of the so-called specific-factor model, ${ }^{7}$ where labor moves freely across industries in response to the wage rate differentials whereas the capital is completely immobile. But it could be plausible argued that there is always some degree of factor mobility in the economy and, on the other hand, it may also be plausible to postulate that no labor is perfectly mobile across industries. In this paper we will incorporate the assumption of labor specificity to develop an approach in which it is possible to consider the implications of a complete range of degrees of labor specificity, and the l ones-Purvis model emerges as a special case. This is the purpose of defining a elasticity to measure the degree of the reallocation of the labor endowment across two "tiers" in response to external shock consisting of a deterioration in the terms of trade. Furthermore, by viewing labor specificity as primarily a short-medium run phenomenon, the logical integration with the ones-Purvis framework is to explain short-medium-run trends in the exchange rates.

In the organization of the paper we will follow the Jones and Purvis format. Thus, we will begin developing the model in section I by assuming only one traded middle product is produced in the "input tier" and only one nontraded good in the "output tier" is produced. In the following sections the רypothesis of diversified production in the two "tiers" will be considered. Thus, in the "input tier," we will study the implications of the existence of import-competing production ( section III), while for a diversified production in the "output-tier" it is possible to study the interaction of tastes and other variables of the model (section IV). Finally, section $V$ contains some concluding remarks.

\section{The Model in a Simplified Economy}

Let us begin writing the production functions of the exported middle product B and non-traded consumption good N which in the "input-tier" and "output-tier," respectively, are produced, 
$B=f\left(K_{B}, L_{B}\right), \quad N=g\left(A, L_{N}\right)$

where $K_{j}$ and $L_{j}$, respectively, denote capital and labor inputs in the $j$ th "tier" $(j=B, N)$, and where $f$ and $g$ are linear homogeneous with constant returns to scale.

From the full employment condition of the fixed overall supply of labor, we may write

$$
a_{L B} B+a_{L N} N=\bar{L}
$$

where $a_{L j}$ is the amount of labor factor used per unit of the $j$ th good.

Totally differentiating the equation (1) we obtain

$$
{ }_{L B} \hat{L}_{B}+{ }_{L N} \hat{L}_{N}=0
$$

where $\lambda_{\mathrm{Lj}}$ is the fraction of the overall supply of labor used in $j$ th production, and $\hat{L_{j}}$ is the relative change ${ }^{8}$ in the demand for labor in the $j$ th tier.

The formal expressions for the relative changes in the demand for labor in each one of two "tiers," are given by ${ }^{9}$

$$
\hat{L}_{B}=-{ }_{B}\left(\hat{W}_{B}-\hat{E}\right), \quad \hat{L}_{N}=-{ }_{A N}{ }_{N}\left(\hat{W}_{N}-\hat{E}-\hat{\bar{P}}_{A}\right)+\hat{N}
$$

where $\lambda_{B}$ and $\sigma_{N}$, respectively, are the elasticity of demand for labor in the "input-tier" (defined so as to be positive), and the elasticity of substitution between labor and middle product imported $A$ to produce the final consumable $N$. On the other hand $w_{j}$ denotes the wages in the $j$ th "tier," and $E$ represents the nominal exchange rate in terms of a third currency in which the world prices of $A$ and $B$ are measured. ${ }^{10} \mathrm{Finally,} \theta_{\mathrm{AN}}$ and $p_{\triangle}$, respectively, denote A's cost share in the "output-tier" and the world price of A. As the

8. In general, as a "^" on a variable the relative change is denoted. Thus, $\hat{L}_{B}$ is $d L_{B} / L_{B}$. 9. In this paper we are interested in the analysis of the impact of a external shock consisting of a deterioration in the terms of trade. Thus, from here (following J ones and Purvis [1983]), we will assume that $\hat{p}_{A}>0$ and $\hat{p}_{B}=0$. This assumption simplifies the analytic treatment considerably without altering any of the substantive conclusions. But the same external shock could be treated from assumptions such as $p_{A}>$ 0 and $\hat{p}_{B}>0$ with $\hat{p}_{A}>\hat{p}_{B}$, or, $\hat{p}_{A}>0$ and $\hat{p}_{B}<0$, among others. Furthermore, the usual cost minimization procedure is assumed. 
change of real consumption $(\hat{N})$ is given by the degree of trade dependence and the deterioration in the terms of trade, ${ }^{11}$ using (3) we have

$$
\begin{aligned}
& \text { LB B } \hat{W}_{B}+\text { LN AN N } \hat{W}_{N}-(\text { LB B }+ \text { LN AN N }) \hat{E} \\
& =\operatorname{LN}_{A N}\left({ }_{N}-1\right) \hat{\bar{P}}_{A}
\end{aligned}
$$

Furthermore, from the zero profit conditions and taking into account that the exchange rate $\mathrm{E}$ must adjust so that nominal income is constant, we have

$$
\hat{p}_{N}={ }_{A N} \hat{\bar{p}}_{A}
$$

Then, the relationship between the wages in the "output-tier" and the nominal exchange rate $E$ is given by

$$
L N \hat{W}_{N}+{ }_{A N} \hat{E}=0
$$

In this stage of the analysis we introduce the assumption of labor specificity between the two "tiers" of the economy. The degree of labor specificity, in an aptitudinal or preferential sense, may conveniently be measured by the elasticity $\beta$ which is defined as

$$
=\frac{\hat{L}_{N}-\hat{L}_{B}}{\hat{W}_{N}-\hat{W}_{B}}
$$

where $\beta \in[0, \infty]$

The smaller (greater) $\beta$ is, the greater (smaller) the degree of labor specificity. The case of null specificity or perfect labor mobility, where $\beta \rightarrow \infty$, corresponds to the hypothesis of the J ones-Purvis model. M oreover, if the values of $\beta$ tend to infinite (that is, labor is freely mobile between "tiers") production relationships will basically be like those of the standard specific factors model analyzed by Jones [1971], among others. However, international trade breaks this symmetry since contact with the world markets does not take place at consumption good markets but at middle product markets. Furthermore, the world prices in the middle product markets are exogenous to the economy, whereas the prices of (non-traded) consumption goods and the exchange rate $E$ are endogenously determined. As a result of 
are turned from the standard specific-factor model as we shall later 8 .

Then, given that the labor specificity is mainly a short-medium nomenon, the values of $\beta,{ }^{12}$ intuitively, represent a measure of the adjustment of the labor endowment across "tiers" in response to differential wage rates arising from imperfect labor mobility.

From (8) we now may obtain

$$
\left({ }_{B}+\right) \hat{\mathrm{W}}_{\mathrm{B}}-\left(\mathrm{AN}_{\mathrm{N}}+\right) \hat{\mathrm{W}}_{\mathrm{N}}+\left(\text { AN N }_{\mathrm{N}} \mathrm{N}_{\mathrm{E}}\right) \hat{\mathrm{E}}={ }_{\text {AN }}(1-\mathrm{N}) \hat{\overline{\mathrm{p}}}_{\mathrm{A}}
$$

The set of equations (5),(7), and (9) may now be solved to obtain the endogenous changes on wage rates $\left(\hat{w}_{B}\right.$ and $\left.\hat{w}_{N}\right)$ and the exchange rate $E$ in terms of exogenous changes in world price of the middle product $A$

$$
\begin{aligned}
& \hat{\mathrm{W}}_{\mathrm{B}}=\frac{\left(\mathrm{F}_{1}+\mathrm{G}_{1}\right)}{\mathrm{C}_{1}+\mathrm{D}_{1}} \hat{\bar{p}}_{A} \\
& \hat{\mathrm{W}}_{\mathrm{N}}=\frac{\left(\mathrm{H}_{1}+\mathrm{G}_{1}\right)}{\mathrm{C}_{1}+\mathrm{D}_{1}} \hat{\bar{p}}_{\mathrm{A}} \\
& \hat{\mathrm{W}}_{\mathrm{N}}-\hat{\mathrm{W}}_{\mathrm{B}}=\frac{\left(\mathrm{H}_{1}-\mathrm{F}_{1}\right)}{\mathrm{C}_{1}+\mathrm{D}_{1}} \hat{\bar{p}}_{A} \\
& \hat{\mathrm{E}}=\frac{\left(\mathrm{I}_{1}+\mathrm{J}_{1}\right)}{\mathrm{C}_{1}+\mathrm{D}_{1}} \hat{\bar{p}}_{\mathrm{A}}
\end{aligned}
$$

where

$$
\begin{aligned}
& \mathrm{C}_{1}=-\quad A N \quad \mathrm{~N} \quad \mathrm{~B} \text {, } \\
& \left.\mathrm{D}_{1}=t_{\mathrm{LN}} \quad \mathrm{AN}_{\mathrm{N}} \mathrm{N}_{\mathrm{LB}} \mathrm{B}\right) \\
& \mathrm{F}_{1}=-_{\mathrm{AN}} \quad \mathrm{LN} \quad \mathrm{B}(1-\mathrm{N}), \quad \mathrm{G}_{1}=\mathrm{AN}_{\mathrm{NN}} \quad \mathrm{AN}(1-\mathrm{N}) \\
& \mathrm{H}_{1}={ }_{A N} \mathrm{~B}_{\mathrm{AN}}\left(1-\mathrm{N}_{\mathrm{N}}\right) \quad \mathrm{I}_{1}=-{ }_{\mathrm{LN}} \text { AN }\left(1-{ }_{\mathrm{N}}\right) \\
& \mathrm{J}_{1}=-{ }_{\text {LN }} \quad \text { LN AN }\left(1-{ }_{\mathrm{N}}\right)
\end{aligned}
$$

From (10)-(13) it can be seen, as in the Jones-Purvis model, the importance of the size of the elasticity of substitution $\left(\sigma_{N}\right)$ in the "output-tier" for determining the direction and magnitude of wage rates and exchange rate $E$ changes. Thus, if $\sigma_{N}>I\left(\sigma_{N}<1\right)$ prevails the substitution (product) effect in derived demand of factors, and an (a) increase (decrease) of wages in the 
er) (equations (11) and (13)).

However, the elasticity $\beta$ is also important for three reasons: first, the smaller (greater) $\beta$ is, the greater (smaller) the difference between the two "tiers" of the behavior of wage rates (equation (12)). In the extreme case in which labor is, as in the 1971 Jones model, freely mobile across two "tiers" (that is, if $\beta \rightarrow \infty$ ), the direction and magnitude of the behavior of wage rates depends on the degree of flexibility technology in the "output-tier". However, in the standard specific factors model the return of mobile factor always moves in the same direction as good prices change. M oreover, from (6), (10), and (11) in our model it could be deduced that the external shock unambiguously lowers labor's real wage. Furthermore, from the former equations, if $\sigma_{\mathrm{N}}>1$ we have that

$$
\hat{\bar{p}}_{A}>\hat{p}_{A}>\hat{w}_{N}=\hat{w}_{B}>0>\hat{r}_{B}
$$

where $r_{B}$ is the factor return which combined with labor is used to produce the middle product exported $\mathrm{B} .^{13}$

Therefore, the proposition of the standard specific-factor model according to which the change in each commodity price must be trapped between the changes in the returns to factors used to produce that commodity is held here. Instead, if $\sigma_{N}<1$ the verification of the above-mentioned proposition depends on certain values of $\gamma_{B}$ and $\sigma_{N}$.

On other hand, in the extreme case where $\beta \rightarrow 0$, from (10) and (11) it follows that if $\sigma_{N}>1$, rise the wage rate in the "output-tier" $\left(\hat{w}_{N}>0\right)$, whereas decrease the wage rate in the "input-tier" $\left(\hat{\mathrm{w}}_{B}<0\right)$. Furthermore, in this case, in equations (6), (10) and (11) it can be demonstrated that the mentioned feature of the standard specific factors model is not verified.

Secondly, from (11) and (13) it follows that the smaller $\beta$ is, the more strongly the wage rate in the "output-tier" and the exchange rate $E$ respond to changes of the world price of the middle product $A$ (e.g., the smaller $\beta$, the larger are $\hat{w}_{N} / \hat{p}_{A}$ and $\left.\hat{E} / \hat{p}_{A}\right)$. Thirdly, for values of $\beta$ lower than infinite -esponses to short-medium run for the exchange rate $E$ and wage rates are derived after the impact of an external shock.

$\begin{array}{lll}- & . \\ & & \end{array}$ 
home country and in the foreign country) of the consumption good after an increase in the world price of the middle product imported A. From equation (6) we know that the magnitude of the change in the price level depends on the percentage of income spent on the imports of $A .{ }^{14}$ Therefore, the difference between two countries in the behavior of consumption price levels, which determine the PPP rate, is given by

$$
\hat{p}_{N}-\hat{p}_{N}^{*}=\left(\text { AN }-{ }_{A N}^{*}\right) \hat{\bar{p}}_{A}
$$

where with an asterisk the variables that refer to the foreign country are denoted. However, by making use of (13) and assuming that the productive structures in both countries are only differed by the degree of labor specificity, the exchange rate between home country's currency and foreign country's currency, the bilateral exchange rate e (hence, the PPP rate would remain fixed) ${ }_{1}^{15}$ can be written as

$$
\hat{e}=\frac{M_{1}\left({ }^{*}-\right)}{Z_{1}} \hat{\bar{p}}_{A}
$$

where

$$
M_{1}=\quad L N \quad A N \quad B \quad L B \quad B(1-N)
$$

and

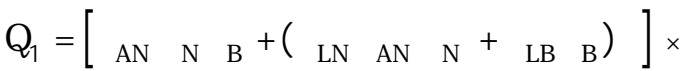

$$
\begin{aligned}
& {\left[\begin{array}{lllllll}
A N & N & B
\end{array}+\left(\begin{array}{llll}
L N & A N & N
\end{array}\right.\right.}
\end{aligned}
$$

The result in equation (15) demonstrates the importance of specificity differentials of the labor force and the size of the degree of flexibility technoloyy in the "output-tier" for the responsiveness of the bilateral exchange rate to the common external shock. Thus, from (15) it follows that

a) For $\sigma_{N}<1$, if $\beta^{*}>\beta$ then $\hat{e}>0$. But if $\beta^{*}<\beta$ then $\hat{e}<0$.

b) For $\sigma_{N}>1$, if $\beta^{*}>\beta$ then $\hat{e}<0$. While if $\beta^{*}<\beta$ then $\hat{e}>0$.

Therefore, in the case in which both countries have the same great difficulty to substitute the middle product imported whose world price 
increased, the country with lower (greater) labor specificity will tend to appreciate (depreciate) its currency relative to the another country's currency. However, if both countries may easily substitute such middle product then the country's currency which has lower (greater) labor specificity will tend to depreciate (appreciate) relative to the other country's currency.

\section{Diversified Productive Structure in the "Input-tier"}

We now suppose that there is some import-competing production of the middle product A in the "input-tier" of each one of two countries. It is also assumed that at the initial prices, the value of output in the "input-tier" is unchanged. Only some home production of A replaces some of the middle product exported $\mathrm{B}$.

Then we can write the production functions of two outputs, B and A, in the "input-tier" as

$$
B=f_{1}\left(K_{B}, L_{B}\right), \quad A=f_{2}\left(K_{A}, L_{A}\right)
$$

where $K_{j}$ and $(j=A, B$ ) denote, respectively, the homogeneous capity and labor used in producing traded middle products $A$ and $B$. The production functions for the two middle products are assumed to be linear homogeneous in their respective inputs and have the standard neoclassical properties of differentiability.

The full employment condition of the labor endowment in the overall economy is now given by

$$
L_{I} \hat{L}_{I}+{ }_{L N} \hat{L}_{N}=0
$$

where $\lambda_{\mathrm{LI}}$ and $\lambda_{\mathrm{LN}}$, respectively, represent the portion of labor endowment employed in the "input-tier" and "output-tier".

On the other hand, the demand for labor in the "input-tier" can be written as ${ }^{16}$

$$
\hat{L}_{1}=-{ }_{1}\left(w_{1}-\hat{E}-z \hat{\bar{p}}_{A}\right)
$$

where $w_{1}$ represents the wage rate in the "input-tier". On the other hand $\gamma_{1}$ 


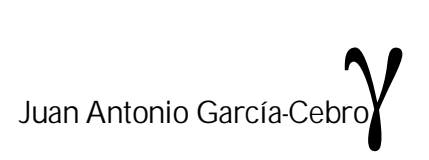

$\beta \mathrm{sm}$

$\begin{array}{lll}\theta & \sigma & \beta\end{array}$

denotes the elasticity of demand for labor in the "input-tier" which is now a weighted average of the separate demand elasticities in each sector of this "tier" $\left(\gamma_{\mathrm{A}}\right.$ and $\left.\gamma_{\mathrm{B}}\right),{ }^{17}$ and $\mathrm{z}$ represents the importance of the A-industry as an employer of labor in the "input- tier" and the importance of the elasticity of labor demand in A-sector relative to $\mathrm{B}$-sector. ${ }^{18}$

The imports of the middle product $A(M)$ are now given by

$$
M=a_{A N} N-x_{A}
$$

where $x_{A}$ represents the home production of $A$.

Let $\theta_{A}$ denote the fraction of income devoted to imports of $A$. The real consumption will not be so severely affected by the deterioration in terms of trade because we now have

$$
\hat{x}_{N}=-{ }_{M} \hat{\bar{p}}_{A}, \quad M<A N
$$

Using (17), (18), and (20) we obtain

$$
\begin{aligned}
& \text { LI I } \hat{\mathrm{W}}_{\text {I }}-\operatorname{LN}_{\mathrm{AN}} \hat{\mathrm{W}}_{\mathrm{N}}-\left(\mathrm{LI},+\operatorname{LN}_{\text {AN N }}\right) \hat{\mathrm{E}} \\
& +\{\operatorname{LN} \text { AN }[N-(\text { M } / \text { AN })]-\operatorname{LI} \quad \mathrm{Z}\}\} \hat{\bar{p}}_{\mathrm{A}}=0
\end{aligned}
$$

On the other hand equation (6) is now replaced by

$$
{ }_{L N} \hat{W}_{N}+{ }_{A N} \hat{E}=-\left({ }_{A N}-M\right) \hat{\bar{p}}_{A}
$$

Finally, we again introduce the possibility that the labor force is specific between the two "tiers". Thus, from (8) we obtain

$$
\begin{aligned}
(1+) \hat{\mathrm{W}}_{1}-\left({ }_{\mathrm{AN}}+\right) \hat{\mathrm{W}}_{\mathrm{N}}+\left({ }_{\mathrm{AN}}-{ }_{1}\right) \hat{\mathrm{E}} \\
=\left({ }_{1} \mathrm{Z}-\mathrm{AN}_{\mathrm{N}}+{ }_{\mathrm{M}}\right) \hat{\overline{\mathrm{p}}}_{\mathrm{A}}
\end{aligned}
$$

Solving equations (21)-(23) then we yield

$$
\hat{\mathrm{W}}_{\mathrm{N}}=\frac{\mathrm{H}_{2}+\mathrm{G}_{2}}{\mathrm{C}_{1}+\mathrm{D}_{1}} \hat{\overline{\mathrm{p}}}_{\mathrm{A}}
$$




$$
\begin{aligned}
& \hat{\mathrm{W}}_{\mathrm{N}}-\hat{\mathrm{W}}_{\mathrm{I}}=\frac{\mathrm{F}_{2}}{\mathrm{C}_{1}+\mathrm{D}_{1}} \hat{\overline{\mathrm{p}}}_{\mathrm{A}} \\
& \hat{\mathrm{E}}=\frac{\mathrm{I}_{2}+\mathrm{J}_{2}}{\mathrm{C}_{1}+\mathrm{D}_{1}} \hat{\overline{\mathrm{p}}}_{\mathrm{A}}
\end{aligned}
$$

where

$$
\begin{aligned}
& \mathrm{H}_{2}=- \text { AN }_{1}\left({ }_{\mathrm{N}}-1\right) \\
& \mathrm{G}_{2}=-{ }_{A N} \mathrm{LI} \quad\left(\mathrm{Z}-{ }_{\mathrm{Al}}\right)-{ }_{\mathrm{AN}} \operatorname{LN} M\left({ }_{\mathrm{N}}-1\right) \\
& \mathrm{F}_{2}=\mathrm{AN}_{\mathrm{N}} \mathrm{N}(\mathrm{Z}-1)+\mathrm{I} \mathrm{M} \\
& I_{2}={ }_{A N}(1-M)\left[N-\frac{L N M}{A N(1-M)}\right] \\
& J_{2}=Q_{A N} \quad L N(1-M)\left[M-\frac{L N M}{A_{A N}(1-M)}\right] \\
& +\mathrm{LI}_{1}\left(\mathrm{Z}_{\mathrm{LN}}+\mathrm{Al} \mathrm{AN}_{\mathrm{AN}}\right)
\end{aligned}
$$

where $\theta_{A 1}$ denotes the percentage of the cost that the A production represents of the total cost in the "input-tier". ${ }^{19}$

From (24)-(26), the following results can be established:

1) The comparison of (13) with (26) reveals that if there is some home production of the middle product imported $A$, a decrease of the exchange rate $E$ is more likely in response to a rise of world price of A. ${ }^{20}$ The likely is larger, the greater the self-sufficiency of the country in the middle product $A$ (that is, the lower $\theta_{M}$ is). M oreover, in equations (24) and (25) it can be observed that the lower $\theta_{\mathrm{M}}$ so much more likely the wages of two "tiers" are isolate from a rise of the world price of $A .^{21}$

2) From the frame of equation (25) it can be seen that in the analysis of the influence of $\beta$ on exchange rate $E$ it is necessary to distinguish two

19. This percentage is given by $\theta_{A I}=\left(\theta_{A N}-\theta_{M}\right) / \theta_{A N}$. 
cases:

a) For values of $\sigma_{N}$ larger than $\theta_{L N} \theta_{M} / \theta_{A N}\left(1-\theta_{M}\right)$ the exchange rate $E$ falls. But if

$$
\frac{\mathrm{LN} M}{\mathrm{AN}\left(1-\mathrm{Z}_{\mathrm{LN}}+\mathrm{AN}_{\mathrm{AN}}+\mathrm{M}_{\mathrm{A}}\right)}>\mathrm{N}>\frac{\mathrm{LN} M}{\mathrm{AN}(1-\mathrm{M})}
$$

the fall of $E$ will be smaller, the greater the labor specificity is. ${ }^{22}$ While if

\section{$\theta$}

$\beta$

$\beta$

then the fall of $E$ will be smaller, the lower the labor specificity is. ${ }^{23}$

b) For values of $\sigma_{N}$ less than $\theta_{L N} \theta_{M} / \theta_{A M}\left(1-\theta_{M}\right)$ the direction of exchange rate $E$ changes is determined by the assumption of labor specificity. Thus from (26) we may obtain if

$$
\left[\frac{L N M}{{ }_{A N}(1-M)} N\right]>\frac{L I \mid\left(Z_{L N}+A_{A I} A N\right)}{A_{N}(1-M)\left({ }_{1}+{ }_{L N}\right)} \text { then } \frac{\hat{E}}{\hat{\bar{p}}_{A}}>0
$$

While if

$$
\left[\frac{L N M}{{ }_{A N}(1-M)}-N\right]<\frac{L_{I}\left(Z_{L N}+A_{A I} \text { AN }\right)}{{ }_{A N}\left(1-{ }_{M}\right)\left({ }_{1}+{ }_{L N}\right)} \text { then } \frac{\hat{E}}{\frac{\hat{p}_{A}}{A}}<0
$$

Therefore, if the values of the elasticity of $A$ substitution are low, larger (lower) is the greater (smaller) the likely of an increase (decrease) of the exchange rate $E$. In the extreme case in which the elasticity $\beta$ tends to zero, it follows that unambiguously the exchange rate $E$ increases.

Finally, from (26) we also obtain the behavior of bilateral exchange rate in the form: ${ }^{24}$

$$
\hat{\mathrm{e}}=\frac{R\left({ }_{M}^{*}-M\right)+M_{2}\left(-{ }^{*}\right)}{Q_{2}}
$$

where 


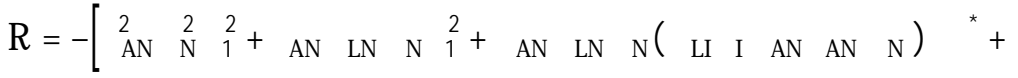

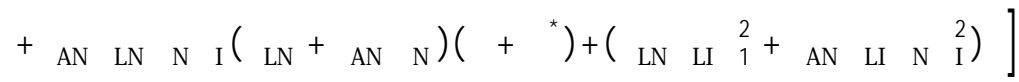

$$
\begin{aligned}
& M_{2}=-M_{A N ~ N}\left({ }_{\mathrm{AN}}\right) \mathrm{LI}_{1}^{2}+\mathrm{AN}_{\mathrm{LI}} \mathrm{N}_{1}^{2}\left[\left(\mathrm{Z}_{\mathrm{LN}}+\mathrm{Al}_{\mathrm{AN}}\right)-1\right] \\
& \mathrm{Q}_{2}=\left[\begin{array}{llllll}
\mathrm{AN} & \mathrm{N} & \mathrm{I} & +( & \mathrm{LI} & \mathrm{I}
\end{array}\right.
\end{aligned}
$$

Equation (26) holds that if the degree of self-sufficiency of the home country is larger (lower) relative to the foreign country there is a trend to appreciate (depreciate) the home currency. But the bilateral exchange rate is also mediated by differentials of labor specificity. Thus, even assuming for both countries the same degree of self-sufficiency, if the labor specificity is lower in the home country than the foreign country $\left(\beta>\beta^{*}\right)$ there is a trend to appreciate the home currency, whereas if the labor specificity is larger in the home country, the trend is now to depreciate the home currency. ${ }^{25}$ Therefore, differentials of labor specificity may increase or reduce the influence of differentials of the degree of self-sufficiency on the behavior of bilateral exchange rate after the impact of the common external shock.

\section{Diversified Productive Structure in the "Output-tier"}

In this section it is assumed that two non-traded consumer goods ( $x_{1}$ and $x_{2}$ ) in the "output-tier" are produced. Thus, it is possible to derive the implications of consumer tastes on the results of previous sections. Then let us write the production functions of these consumer goods as

$$
x_{1}=g_{1}\left(A, L_{N}\right), \quad x_{2}=g_{2}\left(B, L_{N}\right)
$$

where $A$ and $B$, respectively, are the traded middle products used in producng final consumption goods $x_{1}$ and $x_{2}$, and $L_{N}$ is the fraction of labor force employed in the "output-tier". We assume that $g_{1}$ and $g_{2}$ are linear homogeneous in labor and middle products (A, B) inputs.

Then, from the full employment conditions for the fixed aggregate supply 
we can write ${ }^{26}$

$$
\begin{aligned}
& { }_{L 1} \hat{x}_{1}+{ }_{L 2} \hat{x}_{2}+\left({ }_{B}+\right) \hat{W}_{B}-\left(L_{L 1 A 1}+{ }_{L 2} B_{2} 2+\right) \hat{W}_{N} \\
& +\left(\begin{array}{lll}
\text { L1 A1 } & 1+ \\
\hline
\end{array} 2 B 22-{ }_{B}\right) \hat{E}=-L_{1} \text { A1 }{ }_{1} \hat{\bar{p}}_{A} \\
& -\left({ }_{1}+{ }_{L N}\right) \hat{W}_{B}+{ }_{L N} \hat{W}_{N}+{ }_{1} \hat{E}=0
\end{aligned}
$$

On the other hand, the assumption of balanced trade implies that

$$
{ }_{1} \hat{\mathrm{x}}_{1}+{ }_{2} \hat{\mathrm{x}}_{2}=-{ }_{M} \hat{\overline{\mathrm{p}}}_{\mathrm{A}}=-{ }_{\mathrm{A} 1} \hat{\bar{p}}_{\mathrm{A}}
$$

where $\theta_{1}$ and $\theta_{2}$, respectively, denote the share of income spent on final consumption goods $x_{1}$ and $x_{2}$.

We now introduce the demand and supply of the final consumption goods. Assuming homothetic preferences and using the zero-profit restrictions for two industries in the "output-tier", ${ }^{27}$ it follows that

$$
\hat{x}_{1}-\hat{x}_{2}+{ }_{D}|| \hat{w}_{N}-{ }_{D}|| \hat{E}=-{ }_{D} \text { A1 } \hat{\bar{p}}_{A}
$$

where $\mu_{\mathrm{D}}$ is the substitution in demand, and $|\theta|=\theta_{\mathrm{L} 1} \theta_{\mathrm{B} 2}-\theta_{\mathrm{L} 2} \theta_{\mathrm{A} 1} \cdot|\theta|>0$ or $|\theta|<0$, depending on whether $x_{1}$ is labor intensive or $A$ intensive in the sense of value. ${ }^{28} \mathrm{Finally}$ we define an aggregate consumer price index $\mathrm{as}^{29}$

$$
\hat{p}_{N}={ }_{1} \hat{p}_{1}+{ }_{2} \hat{p}_{2}
$$

where $p_{1}$ and $p_{2}$, respectively, denote the prices of the consumer goods $x_{1}$ and $x_{2}$. On the other hand, since balanced trade is assumed, the exchange ate $\mathrm{E}$ changes must involve that

\section{M oreover, we also have use of that}

$$
\hat{a}_{\mathrm{L} 1}=-\theta_{\mathrm{A} 1} \sigma_{1}\left(\hat{w}_{\mathrm{N}}-\hat{\mathrm{E}}-\hat{p}_{\mathrm{A}}\right)
$$

and

$\hat{a}_{\mathrm{L} 2}=-\theta_{\mathrm{B} 2} \sigma_{2}\left(\hat{\mathrm{w}}_{\mathrm{N}}-\hat{\mathrm{E}}\right)$

where $\theta_{\mathrm{A} 1}$ and $\theta_{\mathrm{B} 2}$ indicate the share of revenue produced by the final consumption goods, and $\sigma_{1}, \sigma_{2}$, respectively, denote the elasticity of factor substitution in producing $x_{1}$ and $x_{2}$.

27. Which requires that the weighted sums of factor prices equal to the respective output prices, where the weights are the amounts of labor and middle product used to 


$$
\hat{p}_{N}=A 11 \hat{\bar{p}}_{A}
$$

Then, from zero-profit condition and using (34) we can write

$$
\left({ }_{1} L_{1}+2 L_{2}\right) \hat{W}_{N}+\left(\begin{array}{ll}
1 & A 1 \\
& 2 B 2
\end{array}\right) \hat{E}=0
$$

Solving (29)-(32) and (35) we can yield the following formal solutions for the effects of a external shock:

$$
\begin{aligned}
& \hat{x}_{1}-\hat{x}_{2}=\frac{R+S}{C_{2}+D_{2}} \hat{\bar{p}}_{A} \\
& \hat{p}_{1}-\hat{p}_{2}=\frac{T+V}{C_{2}+D_{2}} \hat{\bar{p}}_{A} \\
& \hat{w}_{N}=\frac{H_{3}+G_{3}}{C_{2}+D_{2}} \hat{\bar{p}}_{A} \\
& \hat{w}_{N}-\hat{w}_{B}=\frac{F_{3}}{C_{2}+D_{2}} \hat{\bar{p}}_{A} \\
& \hat{E}=\frac{I_{3}+J_{3}}{C_{2}+D_{2}} \hat{\bar{p}}_{A}
\end{aligned}
$$

Where the formal expressions for $R, S, T, V, H_{3}, G_{3}, F_{3}, I_{3}, J_{3}, C_{2}$, and $D_{2}$ are written in the appendix 1.

The results (36)-(40) show the role of taste patterns interacting with other structural variables (among these, the labor specificity) for the responsiveness of the endogenous variables to an increase of the world price of the middle product imported $A$. This generic result may be seen more clearly in the two extremes cases of tastes:

1) If individuals resist any change in the proportions in which the consume final goods (that is, when the elasticity of substitution in demand tends to zero), we obtain the following results:

(i) From (36) and (37) it follows that the external shock is adjusted by changes of relative prices of the final consumption goods.

(ii) Equations (38), (39) and (40) hold that the degree of flexibility of technologv in the "output-tier" and the dearee of labor specificity 
2) If the consumer goods are perfect substitutes (that is, if the elasticity of substitution in demand tends to infinite), we have

(i) The external shock does not alter the relative price of consumer goods, but only the relative consumption of both final goods.

(ii) In this case, equations (38), (39) and (40) reveal that the determinants of the behavior of labor incomes and the exchange rate $E$ are not the degree of flexibility of technology in the "output-tier" neither the degree of labor specificity, but factor intensities of final consumption goods.

Finally, from (40), we may once more obtain the behavior of the bilateral exchange rate e supposing that the home country has a taste and labor specificity bias (compared with the foreign country):

$$
\hat{\mathrm{e}}=\frac{V\left({ }_{\mathrm{D}}^{*}-\mathrm{D}_{\mathrm{D}}\right)+\mathrm{M}_{3}\left({ }^{*}-\right)}{\mathrm{Q}_{3}} \hat{\bar{p}}_{\mathrm{A}}
$$

where $\mathrm{V}, \mathrm{M}_{3}$ and $\mathrm{Q}_{3}$ are coefficients whose expressions are given in the appendix 2.

From equation (41) it follows that differen fials of taste pattern sinteracting with differentials of labor specificity are important for determining the direction and magnitude of bilateral exchange rate changes. Thus, for high values of $\sigma_{1}$ and if the consumption good in which production is used the niddle product imported is labor intensive (in a physical sense), a sufficient condition to appreciate home currency is that

$$
{ }_{D}^{*}>\mathrm{D}<\frac{\mathrm{L} 1\left(1-\frac{1}{\mathrm{~L} 1}\right)}{||} \text { and }{ }^{*}>\text {. }
$$

While a sufficient condition to depreciate home currency would be that

$$
{ }_{\mathrm{D}}^{*}<\mathrm{D}<\frac{\mathrm{L} 1\left(1-\frac{1}{\mathrm{~L} 1}\right)}{\mathrm{I}} \text { and }{ }^{*}<.
$$

Therefore, in this section and in previous sections, we have obtained that

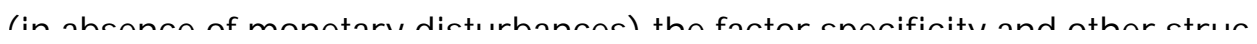


external common shock. F urthermore, since the real exchange rate is measured as the nominal exchange rate adjusted for changes in the general price level, these interactions between real or structural variables may be important in assessing the recent empirical literature on real exchange rate dynamics. Thus, as we have already seen in section I, there does seems to be long-run convergence to PPP in testing the real exchange rate as random walk. ${ }^{30}$ However, such as Froot and Rogoff [1995] suggest "survivorship" bias might exaggerate the extent to which PPP holds in the long-run. Even it might be thought of that the former conclusion is outcome of selecting country currencies with a similar structural characteristics of their economies (for example, franc/ pound or dollar/ pound in Lothian and Tayor [1996]). But if both countries were very different in relation to their structural variables ${ }^{31}$ from our model one could think of systematic and persistent deviations from PPP rate. In fact, Froot and Rogoff [1995], to intuitively gauge the importance of this sample-selection effect, consider data for the Argentine peso/ US dollar and the Argentine peso/British pound Jver the period 1913-1988, and they seem to conclude that it is not possible to reject the presence of a unit root here. In another scene, this result is also confirmed in Lippert and Breuer [1995]. They find that the cause of PPP violations is in the omission of real factors of the economies within the empirical tests. Therefore, in this paper we have draw on a theoretical framework which is consistent with the former observations.

A second implication of our model is that the assumption of factor specificity introduces a short-medium-run impact on the real exchange rate in response to a common external shock. Then, although this model is not explicitly dynamic, by means of labor specificity changes it is possible to derive a short-medium-run path for real exchange rates in the structural models in which deviations from PPP depends on supply factors, and to extend this analysis to demand factors in line with some empirical works such as De Gregorio, Giovannini, and Wolf [1994].

30. See Froot and Rogoff [1995, p.1659]. 


\section{Concluding Remarks}

While the paper has not exhausted the range of problems that may be studied with the model developed here, it seems clear that the incorporation of the assumption of factor specificity in the models of exchange rate determination whose focus of the analysis is on structural, or real, characteristics of the economy, improves the explanation of systematic and persistent deviations from PPP at short-medium run horizons. In particular, four features of the model are noteworthy.

Firstly, if there are differences between countries in the degree of labor specificity it is possible to explain persistent and systematic deviations from PPP exchange rate in response to a common external shock.

Secondly, the magnitude and direction of the effects of labor specificity differentials depend on other structural variables such as the degree of flexibility of technology, the degree of self-sufficiency, and tastes. In this framework, labor specificity, technology, and tastes interact to determine the behavior of the exchange rates. Thus, some results derived were: for the same low degrees of flexibility of technology in two countries, the country whose labor specificity is smaller (larger) should tend to appreciate (depreciate) its currency (relative to the other country's currency). However, for the same high degrees of flexibility of technology, the former conclusion is reversed. On the other hand, we have demonstrated that if the taste patterns are such that the final consumption goods are perfect substitutes, then there is not any influence of the labor specificity in the behavior of exchange rates.

Thirdly, since the factor specificity is primarily a short-medium run phenomenon the model of this paper, although it is not explicitly dynamic, presents a structural focus for the analysis of the impact on short-medium run to long-run bilateral exchange rate movements, in response to a common external shock, and without influence of monetary factors. M onetary factors may of course distort PPP in the short-run, but these phenomena could -eadily be incorporated, for example, such as were introduced by Dornhusch [19761. However. in this naner we are onlv interested in the structural 
(that is, when the values of the elasticity in which the labor specificity is measured, tend to infinite) it could readily be proved that both the JonesPurvis model and this paper model's results are equal. Therefore, the model of this paper generalizes the 1983 J ones-Purvis model.

\section{References}

Adler, M . and B. Lehmann [1983], "Deviations from Purchasing Power Parity in the Long Run," Journal of Finance 38; pp. 1471-1487.

Aizenman, J. [1984], “M odeling Deviations from PPP," International Eco nomic Review 25; pp. 175-190.

Asea, P.K. and E. M endoza [1994], "The Balassa-Samuelson M odel: A General Equilibrium Appraisal," Review of International Economics 2; pp. 244-267.

Balassa, B. [1964], “The Purchasing Power Parity D octrine: A Reappraisal," Journal of Political Economy 72; pp. 584-596.

Bhagwati J.N . and T.N. Srinivasan [1983], Lectures in the Theory of International Trade (M .I.T. Press, Cambridge, M ass.)

Daniel, B.C. [1986], "Sticky Prices and Purchasing Power Parity Deviations: Empirical Deviations," Economic Letters 20; pp. 187-190.

De Gregorio, J., A. Giovannini, and H. Wolf [ 1994], "International Evidence on Tradables and Nontradables Inflation," European E conomic Review 38; pp. 1225-1244.

Dornbusch, R. [ 1976], “Expectations and Exchange Rate Dynamics," Jour nal of Political Economy 84; pp. 1161-1176.

Dornbusch, R. [1985], "Purchasing Power Parity" NBER, Working Paper No. 1591.

Frankel, J .A. and A.K. Rose [1996], "A Panel Project on Purchasing Power Parity: Mean Reversion within and Between Countries," Journal of International Economics 40; pp. 209-224.

Frenkel, J. [1981], "The Collapse of Purchasing Power Parities During the 1970s" European E conomic Review 16; pp. 145-165.

r.... 
Hsieh, D. [1982], "The Determination of the Real Exchange Rate: The Productivity Approach," Journal of International Economics 12; pp. 355362.

I ones, R. W. [1971], "A Three Factor M odel in Theory, Trade, and History" in Bhagwati, J. N. et al., Trade, the Balance of Payments, and Growth (North-Holland, Amsterd.).

I ones, R.W. and D. Purvis [1983], "International Differences in Response to Common External Shocks. The Role of Purchasing Power Parity," in Classen E. and P. Salin eds., Recent Issues in the Theory of Flexible Exchange Rate (North-Holland, Amsterd.).

Kierzkowski, H. [1987], "Recent Advances in International Trade Theory: A Selective Sur vey," Oxford Review of E conomic Policy 3, N o. 1, 1-19.

Lippert, A. F. and J. B. B reuer [1995], "Purchasing Power Parity and Real factors," Applied Economics 26; pp. 1029-1036.

Lothian, J. and M. Taylor [1996], "Real Exchange Rate Behavior: The Recent Float from the Perspective of the Past Two Centuries," Journal of Political Economy 104; pp. 488-509.

M cDonal, R. [1996], "Panel Unit Root Test and Real Exchange Rates," Eco nomics Letters 50; pp. 7-11.

Magge, S. [1976], International Trade and Distortions in Factor M arkets (D ekker, N ew York].

M ark, N.C. [1990], "Real and Nominal Exchange Rates in the Short Run and in the Long Run: An E mpirical Investigation," Journal of International E conomics 28; pp.115-136.

M arston, R. [1987], "Real Exchange Rates and Productivity Growth in the United States and Japan," in Arndt, S, and J. D. eds., Real Financial Linkages Among Open Economies (M .I.T. Press. Cambridge, M ass.)

Mayer, W. [1974], "Short Run and Long Run Equilibrium in Small Open Economy," Journal of Political E conomy 82; pp. 955-967.

M ussa, M . [1974], "Tariffs and the Distribution of Income: The Importance of Factor Specificity, Substitutability, and Intensity in the Short and Long Run," Journal of Political Economy 82; pp. 1191-1203.

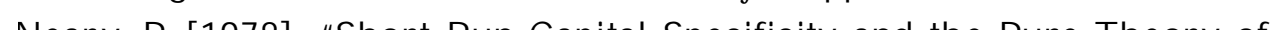


34; pp. 167-180.

Samuelson, P.A. [1964], "Theretical Notes on Trade Problems," Review of E conomics and Statistics 46; pp. 145-164.

Samuelson, P.A. [1971], “Ohlin Was Right,” Swedish Journal of E conomics 73; pp. 365-384.

Sanyal, K.K. and R.W. J ones [1982], "The Theory of Trade in M iddle Products," American E conomic Review 72; pp. 16-31.

Sharma, M. K. and R. Obar [1995], "Testing for Purchasing Power Parity: A Data $M$ atching Problem or a Long-Run Phenomenon?," M ultinational Business Review 3; pp. 74-81.

Snell, A. [1996], "A Test of Purchasing Power Parity Based on the Largest Principal Component of Real Exchange Rates of the OECD Economies," E conomics Letters 51; pp. 225-231.

Wei, S. J. and D. Parsley [1995], "Purchasing Power Disparity During the Floating Rate Period: Exchange Rate Volatility, Trade Barriers, and Other Culprits" NBER Working Paper No. 5032.

\section{Appendix 1}

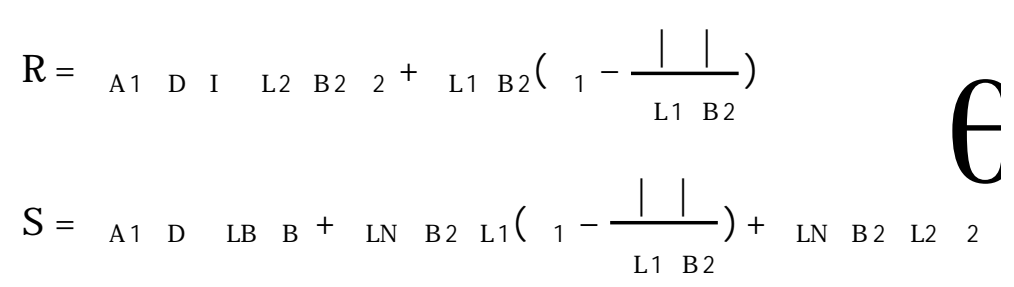

$$
\begin{aligned}
& T=-A_{1} 1_{1}\left[\begin{array}{llll}
L_{2} B_{2} & 2+ \\
\hline
\end{array}\right. \\
& V=-A_{1} L B B-A 1 \quad L N \quad B 2\left[L_{1}\left({ }_{1}-\frac{||}{L 1 B 2}\right)+\begin{array}{ll}
L 2 & 2
\end{array}\right]
\end{aligned}
$$

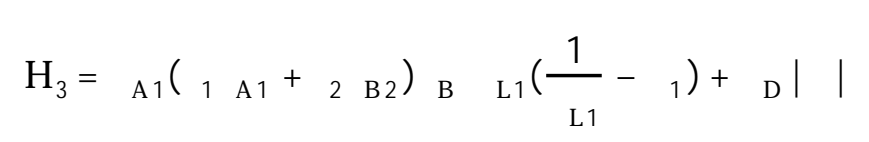




$$
\begin{aligned}
& \mathrm{F}_{3}=A 1 B\left[\mathrm{LI}\left(\frac{1}{\mathrm{~L} 1}-{ }_{1}\right)+{ }_{D} \mid\right] \\
& I_{3}=-{ }_{A 1}\left({ }_{1 L 1}+{ }_{2 L 2}\right) B\left[L_{1}\left(\frac{1}{L 1}-{ }_{1}\right)+{ }_{D}||\right] \\
& J_{3}=-A_{1}\left(1_{1 L 1}+2 L 2\right) L N\left[L 1\left(\frac{1}{L 1}-{ }_{1}\right)+D_{D} \mid\right]
\end{aligned}
$$

$C_{2}=-\left(L_{11 A 1} A_{1}+L_{2} B_{2} 2+D \mid\|\| B\right.$

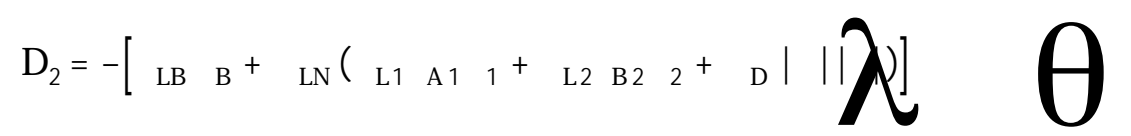

where $|\lambda|=\lambda_{L 1} \theta_{2}-\lambda_{L 2} \theta_{1} \cdot|\lambda|>0$ or $|\lambda|<0$ depending on whether $x_{1}$ is labor intensive in the physical sense. ${ }^{32}$

\section{Appendix 2}

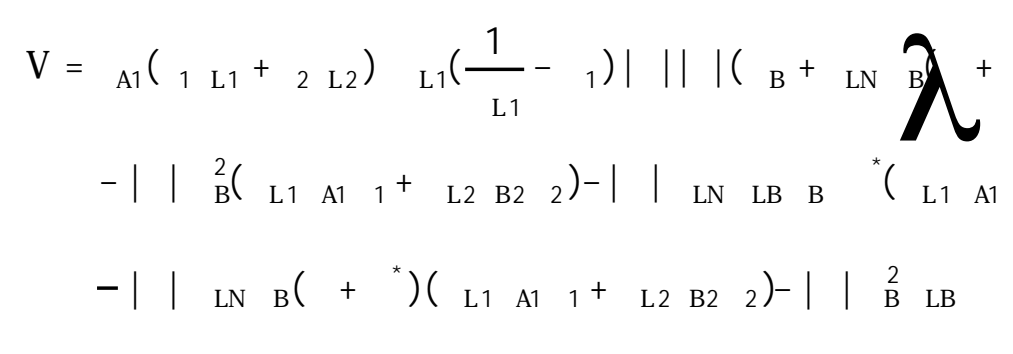

$$
\begin{aligned}
& M_{3}={ }_{A 1}(1 L 2+2 L 2)\left[\left(\frac{1}{L 1}-1\right) L 1{ }_{B}^{2} L B+D|| \begin{array}{lll}
2 & L B
\end{array}\right]
\end{aligned}
$$$$
Q_{3}=\left\{\left(\begin{array}{lll}
L 1 & A 1 & 1
\end{array} L_{L 2} B 22+D|\||\right)_{B}+\left[\begin{array} { l l } 
{ L B } & { B }
\end{array} { } _ { L N } \left(\begin{array}{lll}
L 1 & A 1 & 1
\end{array}\right.\right.\right.
$$

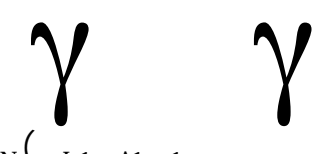

$\begin{array}{lll}\lambda & \theta & \sigma\end{array}$

$\begin{array}{llll}\mu & \lambda & \theta & \beta\end{array}$

$+\angle 2 B 22+D|\||)]\}\left\{\left(L L A 11+\angle 2 B 22+{ }_{D}^{*}|\||\right)_{B}\right.$

$\left.+\left[\ldots+\ldots 1 \ldots+\ldots+\ldots+11111{ }^{*}\right\rceil\right]$ 